\title{
Extraction and characterization of gelatin from Lates niloticus and potential industrial applications
}

\author{
CHEBON SAMMY KIPLAGAT ${ }^{1}$, JOHN MMARI ONYARI $^{1, \bullet}$, FRANCIS MULAA $^{2}$, JOHN WABOMBA $^{1}$ \\ ${ }^{1}$ Department of Chemistry, University of Nairobi. Nairobi, Kenya.`email: jonyari@uonbi.ac.ke \\ ${ }^{2}$ Department of Biochemistry, University of Nairobi. Nairobi, Kenya
}

Manuscript received: 31 July 2016. Revision accepted: 21 March 2017.

\begin{abstract}
Kiplagat CS, Onyari JM, Mulaa F, Wabomba J. 2017. Extraction and characterization of gelatin from Lates niloticus and potential industrial applications. Biofarmasi J Nat Prod Biochem 15: 53-64. This research aims to extract and characterize gelatin from Lates niloticus (Nile perch) scales, then blend it with polyvinyl alcohol (PVA). Hydrolysis of the scales was done using a crude alkaline protease harvested from a bacterium, Bacillus cereus strain wwcp 1, obtained from Lake Bogoria. The lyophilized solution yielded $16.3 \%$ of gelatin powder calculated from the dry weight of the scales. The sample was characterized using infrared spectroscopy and showed peaks at $3442 \mathrm{~cm}^{-1}, 1653 \mathrm{~cm}^{-1}$, and $\sim 1590 \mathrm{~cm}^{-1}$ corresponding to Amide A, Amide I, and Amide II bands, respectively. The amino acid analysis shows that glycine was the most abundant amino acid (21.7\%), followed by a proline (14.6\%) and alanine (11.8\%). Isoleucine, Histidine, and Tyrosine were the least abundant $(1.8,1.4$, and $0.9 \%$, respectively). Polyvinyl alcohol-gelatin blend films of various compositions ranging from $10 \%$ to $90 \%$ PVA were prepared using the solution casting method. Differential Scanning Calorimetry (DSC) and Thermo-gravimetric Analysis (TGA) tests showed the films had glass transition, melting, and thermal decomposition onset temperatures intermediate between those of the respective individual polymers (PVA and gelatin). The thermal stability of the films reduced with the increase in the amount of the less thermally stable constituent. Lastly, potential applications of the prepared blend films were investigated. Batch experiments to assess the potential of the polymer blend films as an adsorbent material were done using Methylene Blue dye. The films were found to adsorb up to $64 \%$ of the dye, and the percentage of dye removal varied with the initial concentration of the dye and contact time.
\end{abstract}

Keywords: Gelatin, industrial applications, Lates niloticus

\section{INTRODUCTION}

Gelatin is a mixture of protein and peptides mainly derived from collagen. Collagen can be found in the skin, bones, cartilage, etc. It is also the most copious structural protein in animals. In humans, collagen makes up a third of the total protein in the human body and makes up 75\% of the total weight of human dry skin (Shoulders and Raines 2009). When collagen is treated with partial hydrolysis, the gelatin will be generated. This also explains why gelatin is a water-soluble polypeptide. This characteristic makes gelatin one of the most used materials in the food and pharmaceutical industries. Depending on its utilization, gelatin can be produced in four grades, i.e., edible, pharmaceutical, photographic, and industrial (Tavakolipour 2011). In the form of an industrial grade, food industries widely use gelatin to perform texturization, gelling, stabilization, and water binding. While in the pharmaceutical industry, gelatin is frequently utilized to produce capsules, tablets, suppositories, and blood plasma substitutes (Nik Aisyah et al., 2014).

Conventionally, gelatin is produced from mammalian sources. A study of the total production output of gelatin found that Bovine and Porcine skins contribute to $46 \%$ of the total amount, Bones and Hooves contribute to $23 \%$ and $29 \%$, respectively, and only $1 \%$ is generated from marine sources (Karim and Bhat 2009; Wang et al. 2010). It is also found that during gelatin production, the destruction of the secondary structure of the parent collagen and some aspects of primary and tertiary structures are inevitable. The production process normally consists of two stages, i.e., the pretreatment step and the main extraction step. In the pretreatment step, the raw materials are prepared for the extraction in either one of the acid pretreatment methods or the alkali pretreatment method, which is to be selected based on the source of the raw materials and the intended purposes of production of the gelatin.

To produce gelatin from connective tissue that exhibits highly interconnected structures such as that of the cattle, alkaline pretreatment is preferred over acid treatment. The alkaline treatment process is applied for up to twenty weeks (Karayannakidis and Zotos 2014). Acid pretreatment is preferred for materials such as pig skin and is usually performed for shorter periods due to a lower degree of collagen cross-linkage. The next stage in the extraction process involves neutralizing the pretreated material to neutral $\mathrm{pH}$ before gelatin is extracted using hot water.

The fish processing industry currently generates solid wastes that can be as high as $75 \%$ of the total weight of the catch. The wastes include scales, guts, heads, skins, and bones and are usually used to produce low-value goods such as fishmeal or are dumped in landfills or water bodies, posing potential environmental harm. The dry mass of fish is largely composed of protein. Therefore, fish processing by-products are candidates for alternative sources of high- 
value protein ingredients such as food-grade gelatin (Karayannakidis and Zotos 2014).

Fish collagen possesses several intrinsic bioactive properties which are beneficial for skin health. It can stimulate skin collagen production and has antiinflammatory, anti-wrinkle, and UV damage repair activity. Collagen has also been widely utilized in the pharmaceutical industry to produce wound dressings, drug delivery vehicles, and vitreous implants. However, Fish collagen has low thermal stability compared to its mammalian counterpart, posing a major problem for biomedical applications. The variation in thermal stability between mammalian and fish collagen is attributed to their amino acid content and distribution of molecular weights (Johnston-Banks 1990).

Amino acids have a key role in stabilizing the collagen helix structure. The amino acid content in mammalian collagen is higher than in fish collagen. Many reports indicated that collagen from cold-water fish contains fewer amino acids than collagen from warm-water fish. Hence, gelatin derived from mammalian sources and warm water fish have a higher melting point than gelatin derived from cold-water fish (Singh et al. 2011). Therefore, it is essential to stabilize fish collagen either physically or microbiologically to produce stable scaffolds for biomedical applications.

There are many fish processing plants in the country where fish filleting (both marine and freshwater fish) is done, both for domestic use and for export to European Union and other markets. Fish scales, a byproduct of that processing, are largely not commercially utilized in Kenya. Furthermore, the government's establishment of an economic stimulus package involving the establishment of fish ponds in all Counties in Kenya has increased the production and consumption of fish, which is expected to produce more scales. This project is aimed at the utilization of fish scale waste generated during fish processing to extract gelatin that was subsequently characterized and the investigation of potential applications.

The scales utilized were from Lates niloticus, commonly known as the Nile perch. This large freshwater fish species found extensively in Lake Victoria, East Africa, can grow up to $200 \mathrm{~kg}$ and two meters in length. Thus, many scales and other byproducts can be obtained from its processing.

The objectives of this research were (i): to extract the gelatin from Lates niloticus scales using a crude alkaline protease from Bacillus cereus strain wwcp 1. (ii) to determine the amino acid composition of gelatin. (iii) to prepare polymer blends containing gelatin and characterize them using FTIR, DSC, and TGA. (iv) to investigate potential industrial applications.

\section{MATERIALS AND METHODS}

\section{Materials}

Fresh Nile Perch (Lates niloticus) skin with intact scales was purchased from the local market in Nairobi, contained in a sealed plastic bag, and transported to the laboratory. Skins more than $1 \mathrm{~kg}$ were selected and stored at $-20^{\circ} \mathrm{C}$ upon arrival if not processed immediately. The scaling process starts with thawing frozen skin at ambient temperature for two hours, washing, and rinsing thoroughly with warm water to help remove any grease from the surface.

After drying up, the skin was scaled on the bench using a knife, and the residual meat or lipids were rinsed entirely under running tap water. The scales were air-dry at ambient conditions, divided into an airtight plastic bag attached with dry weight information.

\section{Enzyme preparation}

Preparation of the crude alkaline protease refers to the method as described elsewhere (Wanyonyi et al., 2014). Briefly, a culture medium containing $0.5 \%$ casein and $0.25 \%$ glucose was prepared at $200 \mathrm{ml}$ each in $500 \mathrm{~mL}$ conical flasks to allow aeration. The medium was then autoclaved at $121^{\circ} \mathrm{C}(15 \mathrm{lb})$ for $15 \mathrm{~min}$ and allowed to cool to room temperature before inoculation. Five percent of overnight-cultured Bacillus cereus strain wwcpl was inoculated into the fresh medium and incubated at a rotary shaker $(140 \mathrm{rpm})$ for 72 hours at $45^{\circ} \mathrm{C}$. Following incubation, the medium was then centrifuged at $5000 \mathrm{rpm}$ for 15 minutes to collect the crude enzyme's supernatant.

\section{Gelatin extraction}

The optimum $\mathrm{pH}$ for gelatin extraction referred to the method established by Wanyonyi et al. (2014). First, the supernatant that contains the crude enzyme was adjusted to $\mathrm{pH} 11$ by using a $\mathrm{pH}$ meter and sodium hydroxide in a glass beaker. The supernatant was then poured over $1 \mathrm{~kg}$ of dry scales, ensuring submerged all parts. Hydrolysis was performed in the oven at $50^{\circ} \mathrm{C}$. Every twelve hours, the $\mathrm{pH}$ of the solution was checked and restored to the optimum value. To ensure homogeneity of the process, the sample was stirred regularly.

Once the scales were completely hydrolyzed, the sample was removed from the oven and cooled down at ambient temperature. To obtain gelatin powder, gelatin solution (the liquid part) was separated by decantation and lyophilized. The yield was determined by the percentage of the total weight of dry gelatin powder per the total weight of dry scales.

\section{Infrared spectroscopy}

The sample's infra-red spectroscopic analysis was performed with minor alterations, as outlined by Muyonga et al. (2004). A $200 \mathrm{mg} \mathrm{KBr}$ disc containing 2-6 mg of the sample disc was prepared and used to obtain the spectrum. The analysis was performed on a Thermo Electron Corporation Nicolet 380 FTIR spectrometer.

\section{Determination of amino acid composition}

Amino acid analysis of Nile perch scale gelatin was performed using a narrow bore $(2.1 \times 200 \mathrm{~mm})$ (Hypersil AA-ODS), $5 \mu \mathrm{m}$ reverse phase column purchased from Thermo Electron (part \# 30105-202130). Samples were weighed and placed into a 13 x $100 \mathrm{~mm}$ Pyrex tube along with $1 \mathrm{ml} \mathrm{N} \mathrm{HCl}$ and $11 \mu$ moles of Internal Standards 
(Norvaline and Sarcosine). After adding the Internal Standards, the samples, controls, and blanks were exposed to liquid-phase $6 \mathrm{~N} \mathrm{HCl}$ for 22 hours at $100^{\circ} \mathrm{C}$. Amino acids were separated on an Agilent 1260 with a column heater, automatic injection programming $\mathrm{UV}$, and fluorescence detection.

Five $\mu \mathrm{L}$ of the hydrolysate was dried down and resuspended in $250 \mu \mathrm{L}$ of $0.4 \mathrm{M}$ Borate buffer. One $\mu \mathrm{L}$ was injected. The G1367E autosampler was used to perform pre-column derivatization and multiple sample handling. The derivatized amino acids were then eluted from the reverse phase column.

Primary amino acids (tagged with OPA, Agilent \#50613335) and secondary amino acids (tagged with FMOC, Agilent 5061-3337) were detected by the Variable Wavelength (UV) detector (G1365D) at 338/390 nm and $266 / 324 \mathrm{~nm}$, respectively. The fluorometric detector (G1321B) monitored the primaries at excitation/emission $340 / 450$ and the secondaries at 266/305. The assay was calibrated by a standard (Agilent 5061-3331) subjected to the same treatment as the samples and control, including hydrolysis. The assay was controlled by a known protein, Human Serum Albumin. An aliquot from the same batch of HSA was run with every assay.

\section{Preparation of polymer blends and films}

The polymer blends were prepared in 90/10, 80/20, 70/30, 60/40, 50/50, 40/60, 30/70, 20/80, and 10/90 PVA/gelatin proportions. The appropriate weights of PVA purchased from Merck (MW 60,000 and a degree of hydrolysis of $98 \%$ ) were weighed out into $100 \mathrm{ml}$ conical flasks and added to $30 \mathrm{ml}$ distilled water at $95^{\circ} \mathrm{C}$. This solution was swirled in a $90^{\circ} \mathrm{C}$ water bath to dissolve the PVA completely. The resulting solutions were labeled A.

Corresponding weights of gelatin were weighed into flasks and added with $10 \mathrm{ml}$ of distilled water. The mixture was transferred to a water bath at $50^{\circ} \mathrm{C}$ and vigorously stirred for 15 minutes to ensure complete dissolution. The resulting gelatin solutions were then labeled solution $\mathrm{B}$. Solutions B were poured into the appropriate solutions A to obtain film-forming solutions (FFS) with the predetermined PVA/gelatin ratios. The film-forming solutions were homogenized with magnetic stirring at room temperature for 30 minutes to ensure complete mixing.

In an attempt to create films with the same thickness, the same amount of FFS was then cast separately onto glass Petri dishes and subsequently placed in a chamber with air renewal circulation and then left to dry at room temperature. When the films had completely dried, it was peeled off from the Petri dishes and sent for further analysis.

\section{Differential scanning calorimetry}

Differential scanning calorimetry data were recorded for pure gelatin, PVA/ gelatin blends, and pure PVA. The tests were performed on a DSC Q100 V9.9 Build 303 (Universal V4.5A TA Instruments), with 1 to $9 \mathrm{mg}$ samples sealed in aluminum pans. Thermal data (I and II heating scans) were recorded at a temperature ranging from -50 to $250^{\circ} \mathrm{C}$.

\section{Thermogravimetric analysis}

Thermogravimetric analysis of pure gelatin, pure PVA, and the PVA/gelatin blends was performed on a TGA Q500 V20.13 Build 39 (Universal V4.5A TA Instruments) machine. The temperature was set between 0 to $200^{\circ} \mathrm{C}$ with sample sizes ranging from 9 to $27 \mathrm{mg}$. The onset decomposition temperature and weight loss profiles were obtained.

\section{Dye adsorption experiments}

Methylene blue dye (MB, $\left.\mathrm{C}_{16} \mathrm{H}_{18} \mathrm{~N}_{3} \mathrm{ClS}\right)$ with a molecular weight of 319.85 and $\lambda_{\max }$ at $664 \mathrm{~nm}$ purchased from RANBAXY Fine Chemicals in Nairobi, Kenya, was used without any refinement. Batch experiments were performed in $100 \mathrm{ml}$ conical flasks at $25^{\circ} \mathrm{C}$. Films prepared from a 60/40 PVA/gelatin (w/w) blend were chosen to examine the adsorption properties.

\section{Calibration curve}

Stock of methylene blue solution $\left(4.0 \times 10^{-5} \mathrm{M}\right)$ were diluted to obtain concentration $2.5 \times 10^{-5}, 2.0 \times 10^{-5}, 1.25 \times$ $10^{-5}, 1.0 \times 10^{-5}$ and $0.75 \times 10^{-5} \mathrm{M}$. Thirty $\mathrm{ml}$ portions of each concentration was measured out into separate $100 \mathrm{ml}$ conical flasks. Samples were then picked from each flask, and the absorbance was measured on a UV-Vis spectrophotometer (Shimadzu UV-mini 1240) at $664 \mathrm{~nm}$. The calibration curve was created by plotting the absorbance against concentration.

\section{Effect of adsorbent concentration}

The variation of equilibrium uptake of methylene blue with adsorbent concentration was determined in $100 \mathrm{ml}$ conical flasks on an orbital shaker at room temperature. The film's varying weights $(0.25,0.50,0.75$, and $1 \mathrm{~g})$ were measured and placed in four separate flasks. Thirty $\mathrm{ml}$ of $0.000025 \mathrm{M}$ methylene blue was then added to each flask. Samples were then collected from each flask at regular intervals, and residual MB concentration was determined using a UV-Vis spectrophotometer (Shimadzu UV-mini 1240 ) at a wavelength of $664 \mathrm{~nm}$.

\section{Effect of initial dye concentration}

The variation of equilibrium uptake of methylene blue with various adsorbent concentrations was determined in $100 \mathrm{ml}$ conical flasks on an orbital shaker at room temperature. Films weighing 0.25, 0.50, 0.75, and $1 \mathrm{~g}$ were measured, placed into four separated flasks, and supplemented with $30 \mathrm{ml}$ of $0.000025 \mathrm{M}$ methylene blue. Samples were then collected from each flask at regular intervals, and the residual $\mathrm{MB}$ concentration was determined using a UV-Vis spectrophotometer (Shimadzu UV mini 1240) at a wavelength of $664 \mathrm{~nm}$.

\section{RESULTS AND DISCUSSION}

\section{Gelatin yield}

In this study, the freeze-drying procedure of gelatin solution yielded $16.3 \%$ of dry gelatin (Figure 1). This amount is comparable to the previously reported gelatin 
yield obtained from the scales of sea brass (Dicentrarchus labrax) using acetic acid (DinçEr et al., 2015). Another group has successfully produced $48.1 \%$ gelatin from cultured carp scales by employing the alkaline protease method. However, the scales were grounded into a fine paste, thus increasing the surface area for enzymatic reaction and proportionally resulting in a higher yield (Jiang 2013).

The long extraction process that took approximately 13 days might contribute to the lower yield of dry gelatin from Nile Perch, possibly because a significant amount of collagenous materials could have been lost. Moreover, since gelatin derived from collagen and the collagen content differ from the raw materials used, the expected yield obtained between species may vary. This might explain the differences in yield in three species of fish that have been examined above.

The type and quantity of cross-links determine gelatin extractability from different tissues in collagens from various tissues (Muyonga et al. 2004). Therefore, it is expected that the yields of gelatin extracted from different tissues will vary. The yield of gelatin obtained in this study $(16.3 \%)$ is higher than that isolated from the head of Mackerel (Scomber scombrus) by using different organic acids with an average yield of $3.5 \%$ (Khiari et al. 2011). It is also different from that reported from skin extraction of farmed Amur sturgeon (19.6\%), catfish (Clarias batrachus) at $27.79 \%$, snakehead (Channa striatus) at $16.57 \%$, red tilapia (Oreochromis niloticus) at $11.75 \%$, pangasius catfish (Pangasius sutchi) at $10.78 \%$, bigeye snapper (Priacanthus macracanthus) at 6.5\% and brown stripe red snapper (Lutjanus vitta) at 9.4\% (Jongjareonrak et al. 2006; Nikoo et al. 2011; See et al. 2010). The yield in this study also differed from that reported for skin extraction from farmed Amur sturgeon at $19.6 \%$, catfish (Clarias batrachus) at $27.79 \%$, snakehead (Channa striatus) at $16.57 \%$, red tilapia (Oreochromis niloticus) $11.75 \%$, pangasius catfish (Pangasius sutchi) 10.78\%, bigeye snapper (Priacanthus macracanthus) 6.5\% and brown stripe red snapper (Lutjanus vitta) at 9.4\% (Jongjareonrak et al. 2006; See et al. 2010; Nikoo et al. 2011).

\section{IR analysis}

The IR spectra of the gelatin obtained from Nile Perch scales show about nine characteristics of IR absorption bands which can be observed from the IR spectrum (Figure 2). These are the amide A, B, and I, as seen through the VII bands. The amide I band is very sensitive and is the most frequently used to study secondary protein configuration. The amide I peak occurs at $1653 \mathrm{~cm}^{-1}$, which corresponds to a combination of a $\mathrm{C}=\mathrm{O}$ stretching vibration of the amide group and N-H bending and usually occurs at $1600 \mathrm{~cm}^{-1}$ to $1700 \mathrm{~cm}^{-1}$ (Ahmad and Benjakul 2011; Nikoo et al. 2011). Amide II primarily results from in-plane NH bending and $\mathrm{CN}$ stretching vibration and reveals less protein conformation than amide I. Other bands are rarely used in protein conformational studies (Nikoo et al., 2011).

The amide I peak absorption of $1653 \mathrm{~cm}^{-1}$ falls within the expected range of 1650 to $1660 \mathrm{~cm}^{-1}$. This value is slightly higher than the absorption of 1630 to $1640 \mathrm{~cm}^{-1}$ observed in other studies (Muyonga et al. 2004a; Nikoo et al. 2011). The higher frequency of the amide I band suggests a higher degree of disruption of intermolecular bonding when gelatin extraction is done at elevated temperatures and for more extended periods (Kittiphattanabawon et al., 2012; Nikoo et al., 2011), as was the case in this study. The amide A in this study is the wide peak occurring at $3442 \mathrm{~cm}^{-1}$. This peak corresponds to NH stretching coupled with hydrogen bonding. Hydrogen bonding between $\mathrm{OH}$ groups of the amino acids in gelatin is responsible for the width (Muyonga et al. 2004b).

As shown in Figure 2, it is evident that the Amide II and Amide III bands arose at $1590 \mathrm{~cm}^{-1}$ and $1230 \mathrm{~cm}^{-1}$, respectively, consistent with observations of Ahmad and Benjakul (2011). The low intensity of Amide III might be caused by weak molecular interaction in gelatins extracted under high-temperature conditions (Muyonga et al. 2004).

\section{Amino acid analysis}

The amino acid composition of gelatin obtained from the Nile Perch is presented in Table 1.

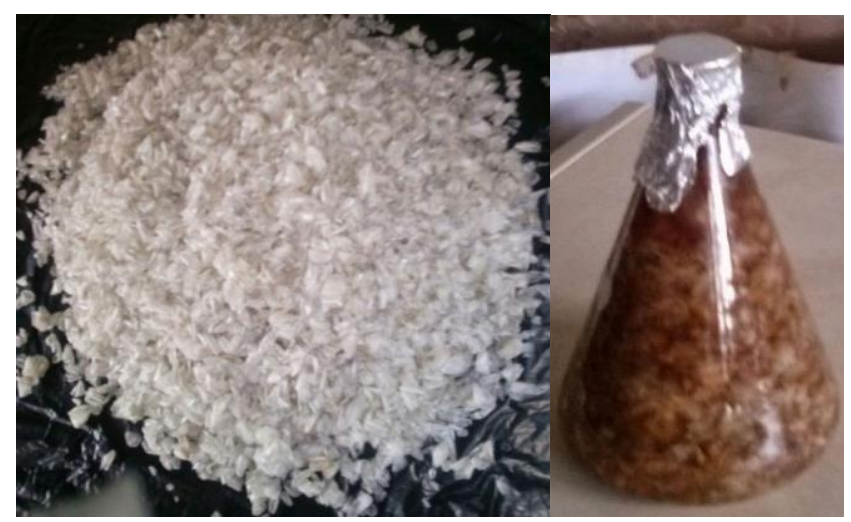

Figure 1. Nile perch scales (left), scales during hydrolysis (right)

Table 1. Amino acid composition of Nile perch scale gelatin

\begin{tabular}{lll}
\hline Amino acid & Composition (weight \%) & SD \\
\hline Asparigine/Aspartic acid & 6.6 & 0 \\
Glutamine/Glutamic acid & 10.8 & 0.0707 \\
Serine & 2.4 & 0.0707 \\
Histidine & 1.4 & 0.1414 \\
Glycine & 21.7 & 0.7778 \\
Threonine & 2.1 & 0.0707 \\
Alanine & 11.8 & 0.2828 \\
Arginine & 8.9 & 0 \\
Tyrosine & 0.9 & 0.2121 \\
Valine & 3 & 0 \\
Methionine & 3.4 & 0.1414 \\
Phenylalanine & 3.1 & 0 \\
Isoleucine & 1.8 & 0 \\
Leucine & 3.3 & 0.0707 \\
Lysine & 4.3 & 0.1414 \\
Proline & 14.6 & 0.7778 \\
Total \% & 100 & \\
\hline
\end{tabular}




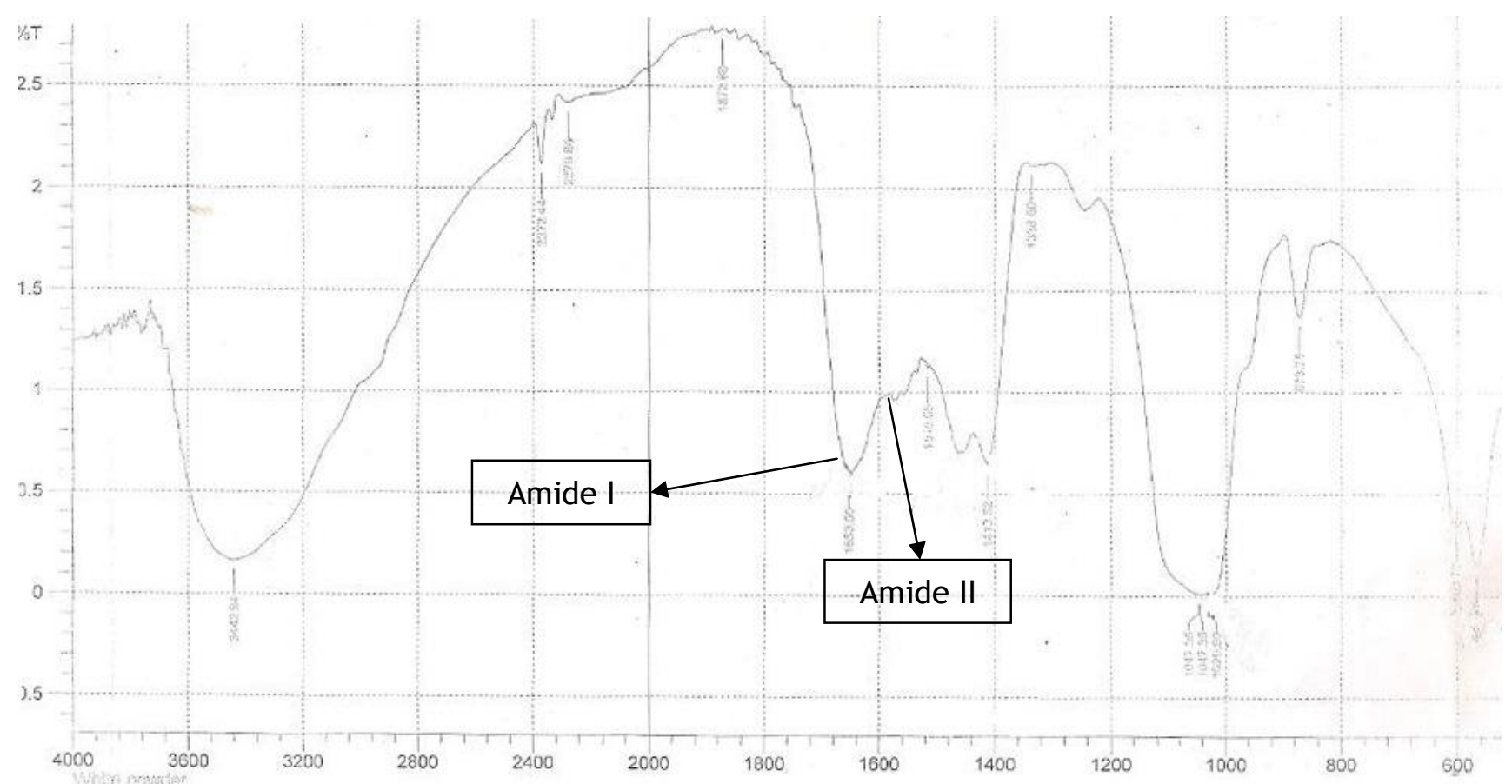

Figure 2. IR spectra of gelatin obtained from Nile perch scales

Among 16 amino acids examined in this study, glycine content was found to be the highest $(21.7 \%)$, followed by a proline $(14.6 \%)$. Gelatin consists of repeating Gly-X-Y motifs corresponding to glycine, proline, and hydroxyproline, respectively. Hence, these amino acids are the most abundant in any gelatin, irrespective of the source. For instance, chicken skin comprises $33.7 \%$ of glycine and $13.42 \%$ of proline, dominating the other types of amino acids present in the skin (Sarbon et al., 2013). Tavakolipour (2011) also reported that gelatin from silver carp fish waste (skins and fins) contains glycine and proline, making up one-third of all amino acid residues at $31.7 \%$ and $12.4 \%$, respectively. The proline content of Nile Perch scale gelatin observed in this study is lower than that of bovine gelatin and porcine gelatin, yet, higher than that seen for Pollock (10.09\%) and Salmon (10.79\%) skin gelatins (Avena-Bustillos et al. 2006). Gelatin from animals that inhabit low-temperature habitats has lower amino acid content than those from animals inhabiting hightemperature habitats. Consequently, fish gelatins have lower amino acid concentrations than mammalian gelatin. Furthermore, warm-water fish tend to have a higher level of amino acids than cold-water fish. In this regard, it can be easily understood that Pollock and Salmon, classified as cold-water fishes, have a lower concentration of total amino acids. Proline and hydroxyproline make up the amino acid complex, which is particularly important in determining the gelatin's gel properties by stabilizing the gel network by hydrogen bonding. The higher the amino acid content is, the better the properties they could make (Gomez-Guillen et al., 2002; Nikoo et al., 2011).
Alanine was another major amino acid found to be the third-highest in its content $(11.8 \%)$ after glycine and proline (Table 1). Alanine occupies the non-polar regions in which gly-pro-y sequences are predominant, with the third position coupled with either hydroxyproline or alanine. Methionine and Threonine were substantially low. The lowest amino acids in composition were tyrosine $(0.9 \%)$, histidine $(1.4 \%)$, and isoleucine $(1.8 \%)$, while tryptophan and cysteine were completely absent. All of these are inherent properties of gelatin (Mahmoodani et al., 2014). The amino acid analysis results were further confirmed in the chromatograms in Figures 3 and 5 b. The height of the peak corresponds to the amount of amino acid.

These findings are similar to the earlier study that reported the absence of tryptophan and cysteine from the list of amino acids analyzed from fish skin gelatin (Karim and Bhat 2009). Nevertheless, another group has also demonstrated that the content of glycine $(19.3 \%)$ and proline $(13,4 \%)$ account for the most abundant type of amino acid in bigeye snapper skins, as was the case in this study (Jongjareonrak et al. 2006).

This is also true for the amino acid profile isolated from the lizardfish scale that yielded three major amino acids, glycine $(18.3 \%)$, proline $(16.5 \%)$, and alanine $(12.4 \%)$. Similarly, threonine and histidine were the least abundant amino acids weighing $0.9 \%$ and $1.52 \%$, respectively (Wangtueai and Noomhorm 2009). One plausible explanation for this similar amino acid profile is that both Nile Perch and lizardfish originated from warm water habitats. 


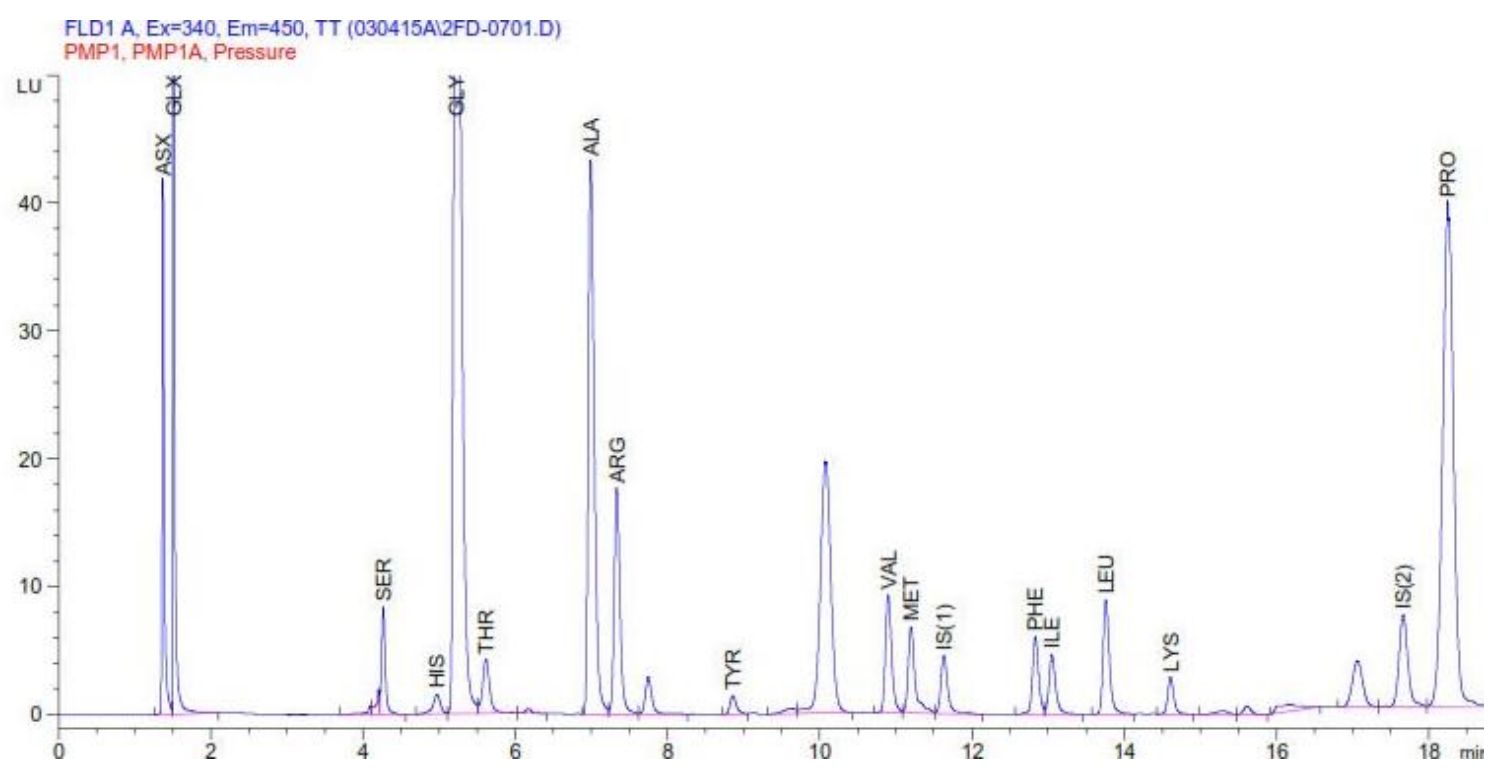

Figure 3.A. HPLC chromatogram of the amino acid analysis of Nile perch scale gelatin, the first repetition

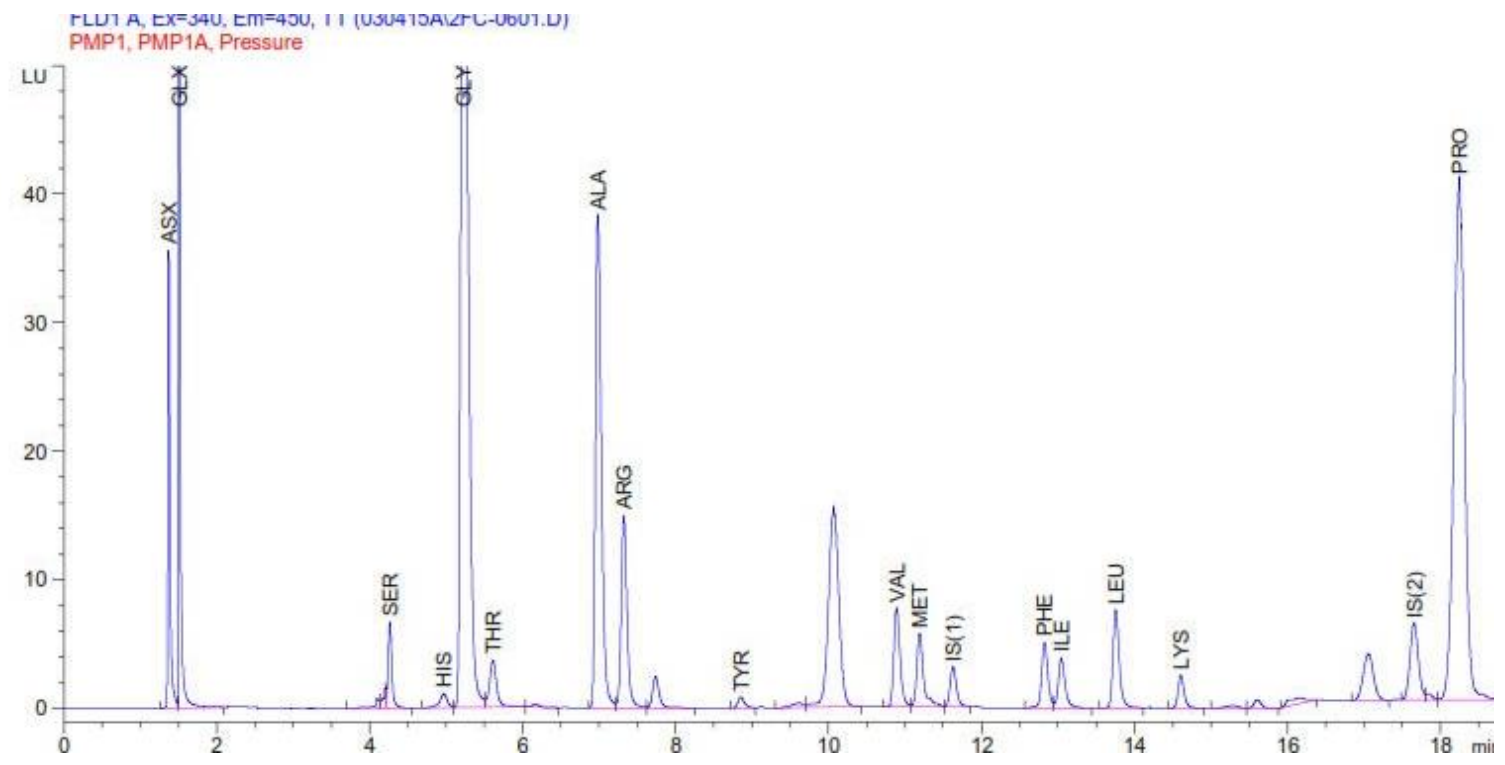

Figure 3.B. HPLC chromatogram of the amino acid analysis of Nile perch scale gelatin, the second repetition

Although amino acid composition might be tissuedependent, to some extent, two different tissues within one species may display a similar profile of amino acids. For example, analysis of gelatin from sea bream bones and scales suggested that the chemical composition of type I collagen is conserved across tissues (Akagündüz et al. 2014). This finding could explain the similarity in the amino acid profiles of Nile Perch bone gelatin (Muyonga et al. 2004a) and that of Nile Perch scales reported in this study. The slight variations could be attributable to the different extraction methods (Amiza et al., 2015). Muyonga et al. (2004a) employed an acid pretreatment before extraction, while in the present study, an enzymatic extraction was used instead.

\section{Blend films preparation}

Figure 4 shows PVA/gelatin blend solutions drying for four days in a petri dish. Once completely dry, PVA/gelatin films of various compositions were peeled off the glass Petri dishes. Figure 5 below shows the 60/40 PVA/gelatin films being peeled off. All films were able to be peeled off except for PVA/gelatin ratios of 10/90. In general, films made from proteins are delicate. Therefore, plasticizers are often added to lower the protein-protein chain interactions stabilizing the film's network and increasing the mobility of protein molecules (Peesan et al. 2005; Vanin et al. 2005). 


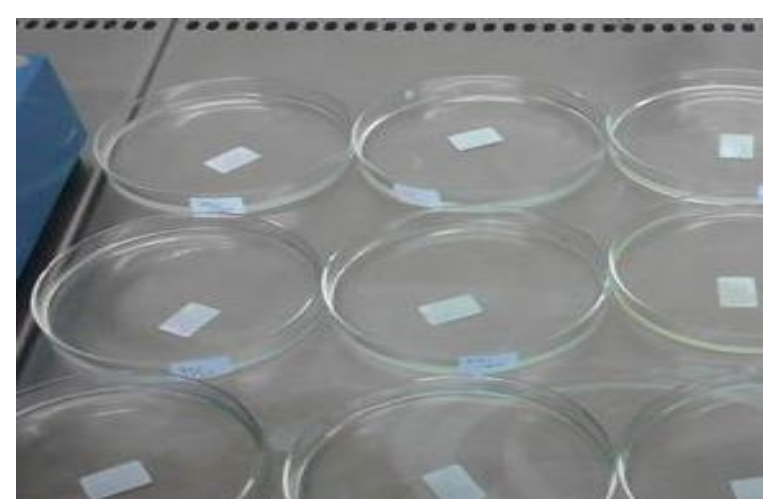

Figure 4. PVA/gelatin solutions of various compositions drying in Petri dishes

In this study, however, no plasticizer was used. Consequently, after completely drying the films, blend films with the highest gelatin content tend to be brittle and difficult to peel off. Gelatin exhibits a strong hydrophilic character and is highly soluble in water. Therefore, it has poor mechanical properties, such as tensile strength in damp environments ( $\mathrm{Yu}$ et al. 2006). The low tensile strength of gelatin explains the ineffectiveness of moisturizing to allow peeling off of the 10/90 blends, unlike other blends containing lower gelatin content.

\section{Thermal analysis of the polymer blends}

\section{DSC Analysis}

DSC analysis of pure gelatin and pure PVA

The DSC thermogram obtained from pure gelatin analysis from Nile Perch scales is shown in Figure 6.

The thermogram shows no endothermic peak except for an inflection corresponding to the glass transition temperature $\left(\mathrm{T}_{\mathrm{g}}\right)$ at approximately $157^{\circ} \mathrm{C}$. The high glass transition temperature suggests a low degree of crystallinity. As a polymer gets more amorphous, its chains become more entangled, thus increasing the amount of energy required to disentangle them during glass transition, raising the temperature of the glass transition (Elsergany 2014). The $T_{g}$ of gelatin in this study exhibits a higher value than that observed by Gao et al. (2014) and Silva et al. (2008), who reported $121.9^{\circ} \mathrm{C}$ and $57.5^{\circ} \mathrm{C}$, respectively. Pawde et al. (2008) reported a much higher value of $220^{\circ} \mathrm{C}$ to $230^{\circ} \mathrm{C}$. $\mathrm{T}_{\mathrm{g}}$ is a kinetic event. Thus, the same substance may have different $\mathrm{T}_{\mathrm{g}}$ s $\mathrm{s}$ as reported in the literature, depending on the manufacturing conditions (Elsergany 2014). As shown in Figure $7, \mathrm{~T}_{\mathrm{g}}$ and $\mathrm{T}_{\mathrm{m}}$ values of $84.9^{\circ} \mathrm{C}$ and $190.8^{\circ} \mathrm{C}$ were obtained for pure PVA.

The endothermic peak indicates semicrystalline properties when the heat of fusion reaches $29.7 \mathrm{~J} / \mathrm{kg}$. Semicrystalline systems typically display a peak after the $\mathrm{T}_{\mathrm{g}}$ transition (Silva et al. 2008), indicative of the melting of the crystalline domains of the polymer. They are absent in the case of amorphous polymers.

\section{DSC analysis of PVA/gelatin blends}

Table 2 summarizes the DSC data obtained for the various compositions of the prepared blends.

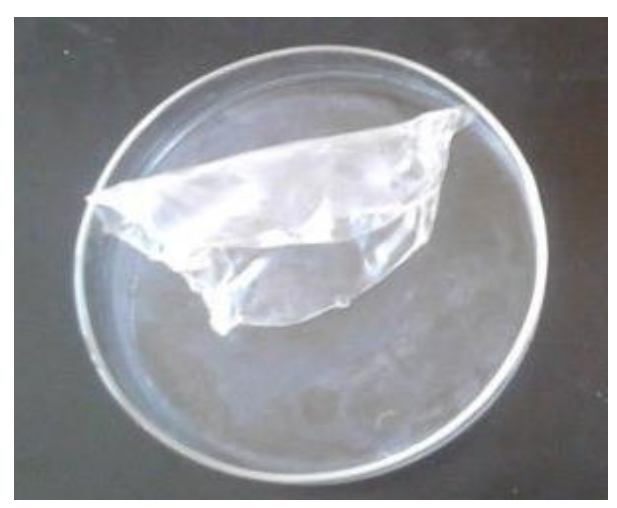

Figure 5. PVA/gelatin films of 60/40 PVA/gelatin composition

The glass transition temperature is used to determine the miscibility of two polymers in the amorphous phase, thereby serving as an essential tool in polymer blend technology. The presence of a single, compositiondependent glass transition temperature intermediate between individual constituents (Peesan et al. 2005) usually indicates the miscibility of polymer blends. Table 2 above represents the DSC data obtained for all the blend films studied.

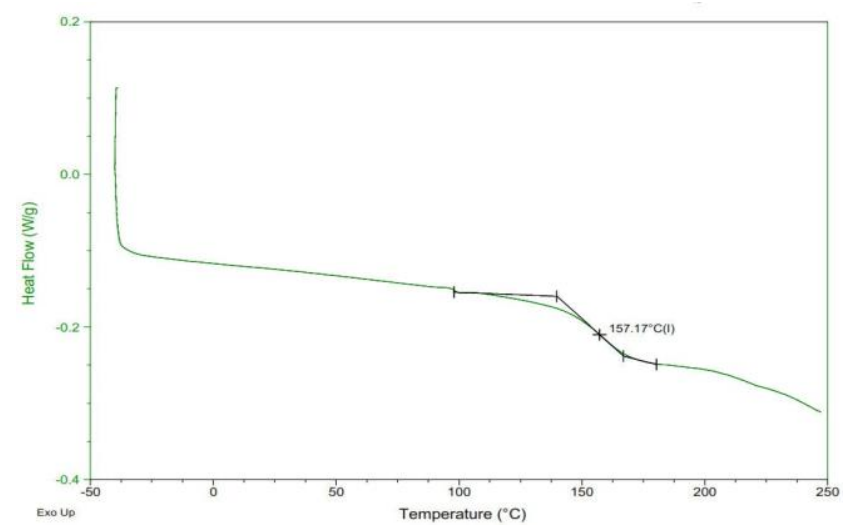

Figure 6. DSC thermogram of gelatin obtained from Nile Perch scales

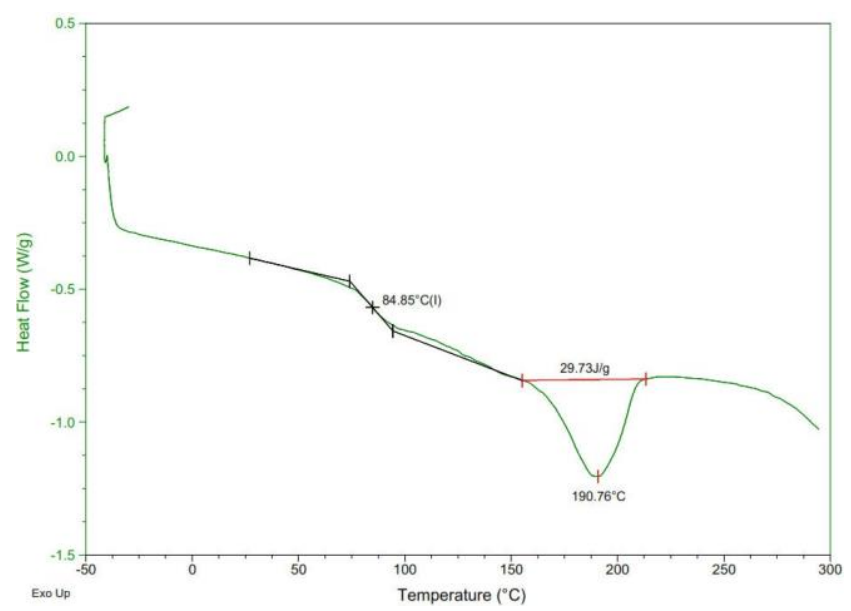

Figure 7. DSC thermogram of pure PVA 
Table 2. DSC data ( $\mathrm{T}_{\mathrm{g}}$ and $\mathrm{T}_{\mathrm{m}}$ ) for PVA/Gelatin polymer blends

\begin{tabular}{lll}
\hline PVA/gelatin & $\mathbf{T}_{\mathbf{g}}\left({ }^{\circ} \mathbf{C}\right)$ & $\mathbf{T}_{\mathbf{m}}\left({ }^{\circ} \mathbf{C}\right)$ \\
\hline $20 / 80$ & 97.14 & - \\
$30 / 70$ & 96.78 & - \\
$40 / 60$ & 97.47 & 187.6 \\
$50 / 50$ & 96.81 & 188.77 \\
$60 / 40$ & 96.95 & 197.88 \\
$70 / 30$ & 96.79 & 207.54 \\
$80 / 20$ & 96.75 & 207.0 \\
90/10 & 87.36 & 173.55 \\
Gelatin 100\% & 157.2 & - \\
PVA 100\% & 84.85 & 190.76 \\
\hline
\end{tabular}

For all films investigated, the $\mathrm{T}_{\mathrm{g}}$ falls in between those observed for gelatin and PVA, and therefore miscibility between PVA and gelatin can be determined. A single $T_{g}$ intermediate between the $\mathrm{T}_{\mathrm{g}}$ 's of the homopolymers implies a higher degree of miscibility in the amorphous phase (Onyari and Huang 2009). It can, therefore, be assumed that miscibility is highest in the $90 / 10 \mathrm{PVA} /$ gelatin blend (Table 2).

This study highlights that the $\mathrm{T}_{\mathrm{g}}$ of the PVA/Gelatin blends studied lies between $96^{\circ} \mathrm{C}$ to $98^{\circ} \mathrm{C}$ for all compositions except 90/10 PVA/gelatin blend film. The relatively constant value of $\mathrm{T}_{\mathrm{g}}$ could be due to the restricted mobility of PVA molecules in the amorphous phase due to the presence of gelatin molecules, as observed by Peesan et al. (2005).

The $T_{g}$ inflections in the DSC curves for all films in this study were followed by significant endothermic peaks, as seen in Figure 8, the DSC thermogram of the 40/60 PVA/gelatin blend.

Melting is a first-order transition ahead of glass transition, which is in the second order. A first-order transition occurs with heat capacity and enthalpy changes, while a second-order occurs with a change solely in the heat capacity (Chiellini et al. 2001; Zhang and Li 2009). This explains the presence and association of the peaks to the melting process (melting peak). The apex of the melting peak gives the melting temperature point $\left(\mathrm{T}_{\mathrm{m}}\right)$ of a polymer, which is the temperature at which the polymer's crystallites lose the highly ordered arrangement in their structure.

Crystalline polymers are characterized by defined melting points, while amorphous polymers are featured with glass transition. The DSC curves of the PVA/gelatin films presented here showed both $T_{g}$ and $T_{m}$ values suggesting semi-crystalline properties, concurring with the findings of other studies (Mendieta-Taboada et al. 2008; Silva et al. 2008). The $\mathrm{T}_{\mathrm{m}}$ of the films occurs between $174^{\circ} \mathrm{C}$ to $207^{\circ} \mathrm{C}$ for different compositions. In the films with 40, 50, and 90\% PVA composition, there is a $\mathrm{T}_{\mathrm{m}}$ depression (187.6, 188.77, and $173.56^{\circ} \mathrm{C}$, respectively) from the observed $\mathrm{T}_{\mathrm{m}}$ value for pure PVA $\left(190.76^{\circ} \mathrm{C}\right)$. This, as observed by Pawde et al. (2008), is indicative of strong intermolecular interactions between PVA and gelatin molecules.

The area under the endothermic peak corresponds to the enthalpy value of fusion of the crystalline portion. It is qualitatively related to the number of crystallites/degree of crystallinity in a film sample. The larger the area, the larger the number of crystallites and the more crystalline a substance is.

The DSC curves of the films of various compositions are shown in Figures 9-13. As the gelatin content increases and the PVA reduces, the size of the area under the endothermic peak decreases, indicating a decline in the level of crystallinity associated with PVA. Almost no endothermic peak is observed in Figure 9. This graph represents the thermogram of the film with PVA and gelatin composition of $30 \%$ and $70 \%$, respectively. The higher the gelatin content in a sample, the more properties resemble gelatins.

Gelatin is amorphous, while PVA is more crystalline. An increase in gelatin or a decrease in the PVA content in the sample films evidently reduces the number of crystallites in the blend samples, as also observed by Pawde et al. (2008).

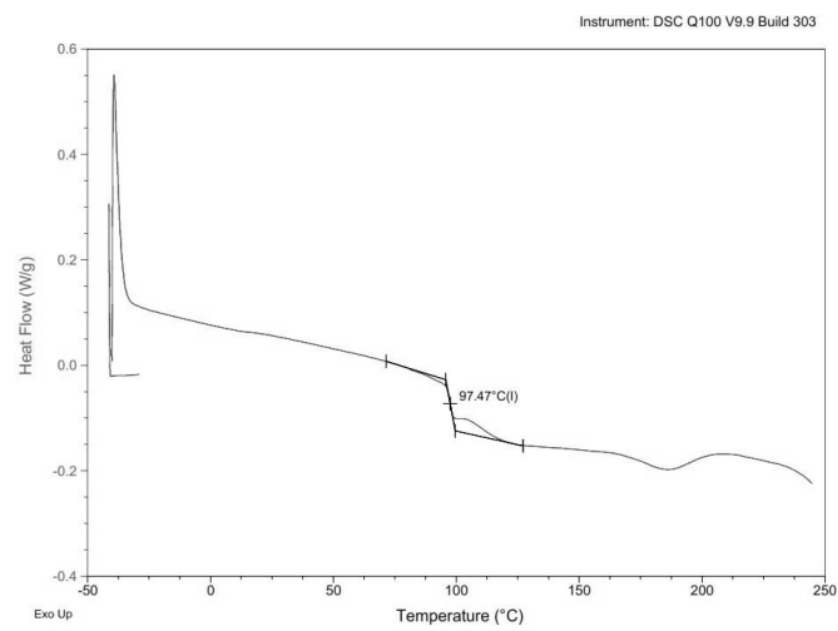

Figure 8. DSC thermogram of PVA/gelatin blend film in 40/60 composition.

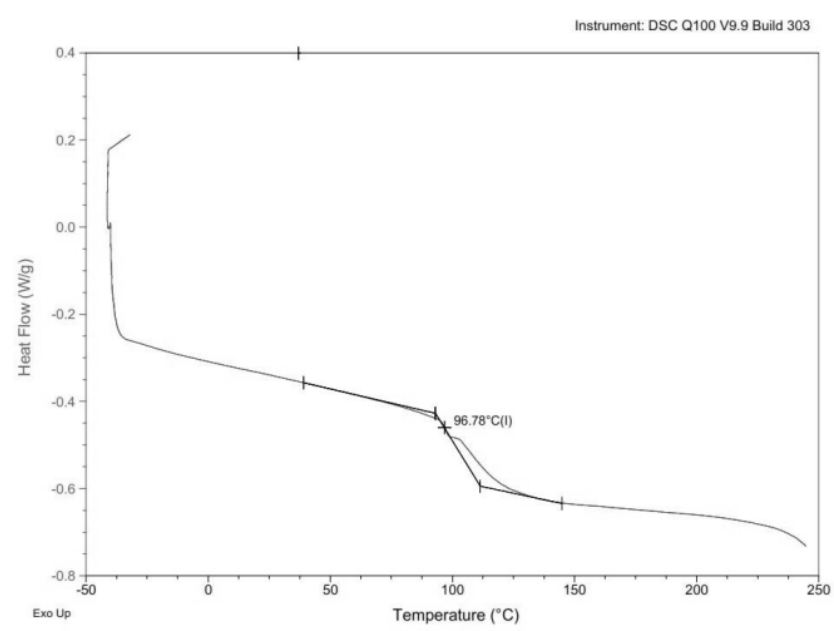

Figure 9. DSC thermogram of the 30/70 PVA/gelatin blend. 
Figure 10 displays the DSC thermogram of the film made of the blend of PVA/ gelatin (50/50\%). As shown above, the effect of PVA amount was prominent since increasing the amount of PVA will effectively increase the area under the endothermic peak. An increase in the quantity of PVA increases the number of crystallites and, therefore, the degree of crystallinity. The phenomenon is further illustrated in the thermogram of the film made from the blend with $70 \%$ PVA composition in Figure 11.

\section{Thermogravimetric analysis}

Thermogravimetric analysis (TGA) is the method of thermal analysis used to evaluate the thermal stability and decomposition behavior of polymer samples over time. A sample is exposed to high temperatures in a controlled environment, and its weight loss profile is plotted against the temperature in the TGA curves. The TGA thermograms of pure PVA and pure gelatin are displayed in Figures 14 and 15 , respectively.

Figure 14 shows the DSC thermograms for the $30 / 70$ PVA/gelatin blend composition film.

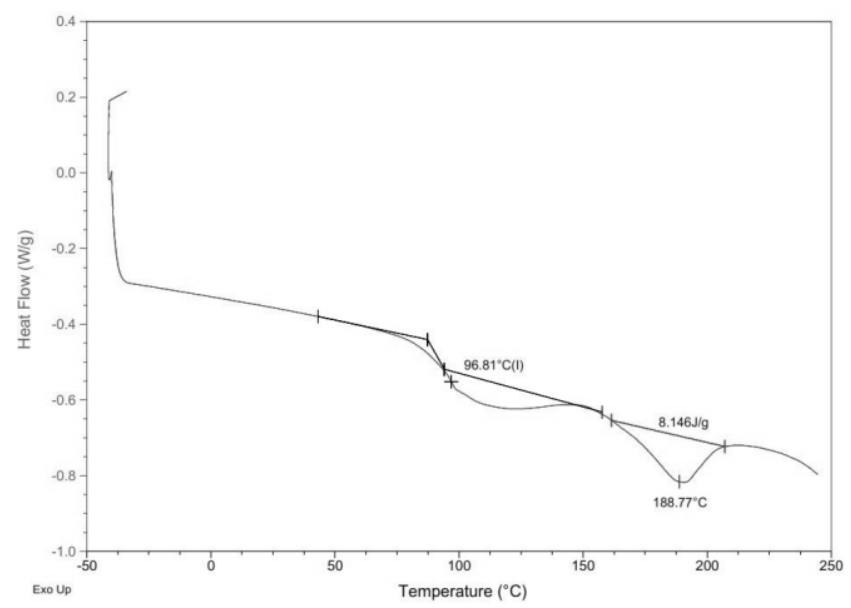

Figure 10. DSC thermogram of 50/50 PVA/gelatin blend film

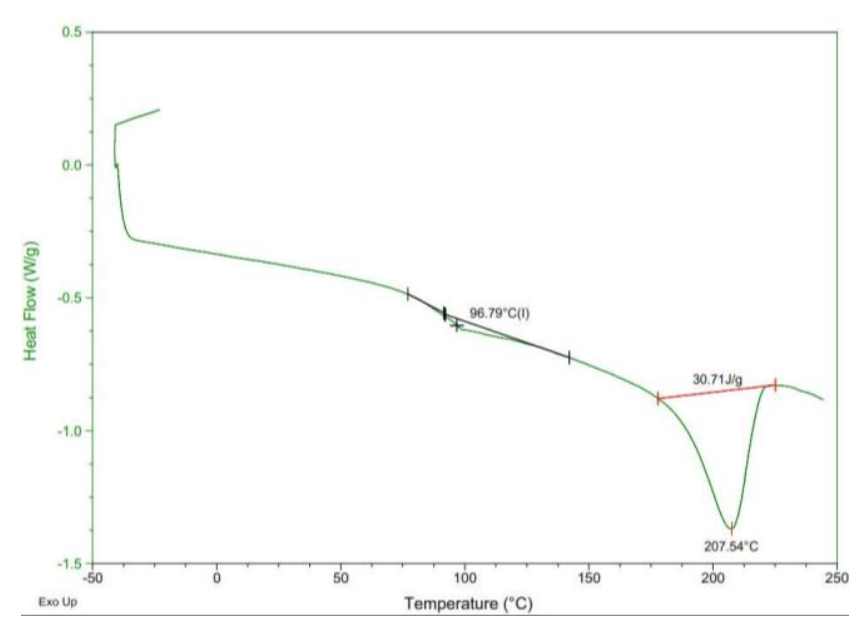

Figure 11. DSC thermogram of 70/30 PVA/gelatin blend film
Both curves show two zones of weight loss. The first regions are due to moisture loss and the evaporation of volatile components. The second region is due to pyrolytic reactions/thermal decomposition. The onset temperature for the decomposition of PVA is approximately $260^{\circ} \mathrm{C}$. After the onset decomposition temperature, the slope of the curve is very steep, indicating a fast decomposition rate. Between $250^{\circ} \mathrm{C}$ and $400^{\circ} \mathrm{C}$, PVA loses most of its weight, remaining with just $20 \%$ at around $400^{\circ} \mathrm{C}$. The rate slows down and completely levels out at about $475^{\circ} \mathrm{C}$. As shown in Figure 12, PVA loses $97.2 \%$ of its weight and a char yield of $2.82 \%$ between the temperature range of $100^{\circ} \mathrm{C}-700^{\circ} \mathrm{C}$.

Previously, Chiellini et al. (2001) reported a difference in temperature of approximately $40^{\circ} \mathrm{C}$. In this study, referring to Figure 13, the degradation of onset temperature was approximately $210^{\circ} \mathrm{C}$, around $50^{\circ} \mathrm{C}$ lower than PVA. Further analysis also revealed that the degradation rate of gelatin is slower than that of PVA. At $400^{\circ} \mathrm{C}$, PVA had lost $80 \%$, while gelatin had lost about $65 \%$ of its weight. Moreover, the slope of the curve of the gelatin is less steep, which explains that gelatin has a char yield of $19.9 \%$ and leads to conclude that gelatin thermally decomposes slower and partially as compared to PVA.

Two regions of weight loss can be attributed to the evaporation of moisture (in the first region) and pyrolytic reactions (in the second region). The onset temperature for the film occurred at $230^{\circ} \mathrm{C}$, an intermediate between the onset temperatures of the individual pure components. Although the curve is not as steep as PVA, it is steeper than gelatin, suggesting an intermediate degradation rate. The film had lost $60 \%$ of its weight at the onset temperature of $400^{\circ} \mathrm{C}$. All these observations display an alteration of individual polymer properties by introducing the other polymer component during blending. The properties of the 30/70 PVA/gelatin blend film are more similar to those of gelatin than PVA, probably due to the higher gelatin content.

The thermal properties of the films are getting similar to that of PVA as the percentage of the PVA in the film increases, i.e., the rate of degradation increases and the residue left at $700^{\circ} \mathrm{C}$ decreases. Figure 15 and 18 display TGA thermograms of the 50/50 and 70/30 PVA/Gelatin blends, which indicate that the thermal stability of the films significantly varies from that of the individual polymers depending on the ratio of each component in the blend. This reduction in thermal stability and an increase in the less stable component were also reported by Chiellini et al. (2001).

\section{Dye adsorption}

This study also aimed at determining the potential industrial applications of the films. The Methylene blue dye was used to examine the potential use of the films in the adsorption of dyes from an aqueous solution. Factors influencing the dye adsorption process, such as contact time, adsorbent amount, and initial concentration, were measured, and the result is given below.

\section{Calibration curve}

The calibration graph for the dilute solutions of methylene blue prepared from a stock solution of 4.0 X 105 is displayed in Figure 17. 


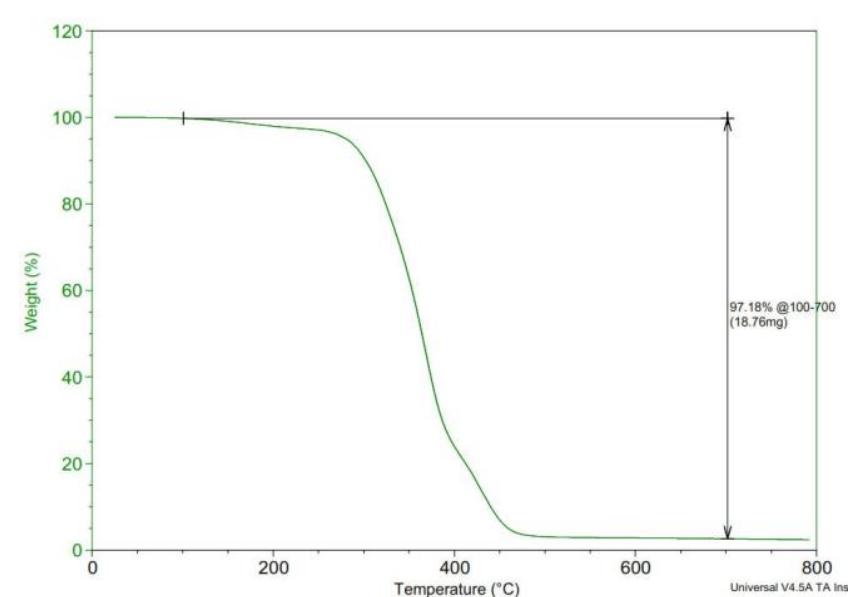

Figure 12. TGA thermogram of pure PVA

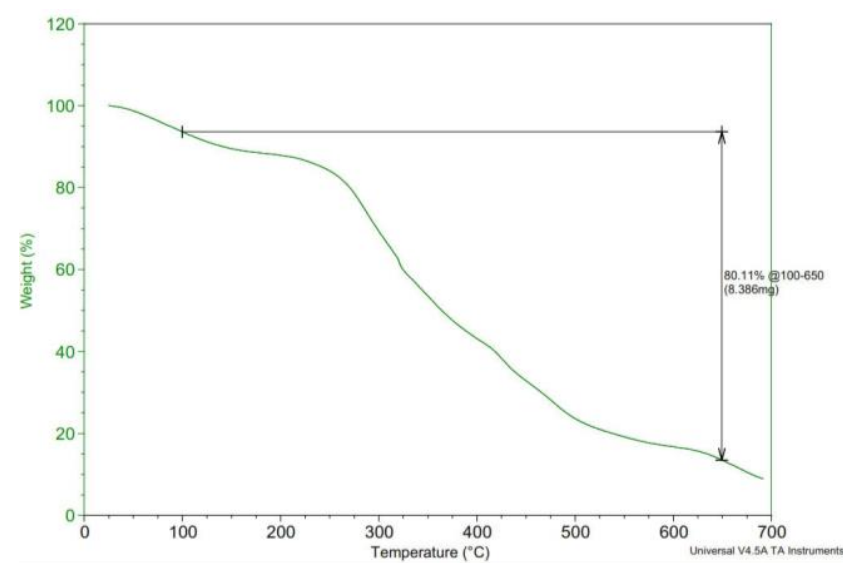

Figure 13. TGA thermogram of pure gelatin obtained from Nile Perch fish scales

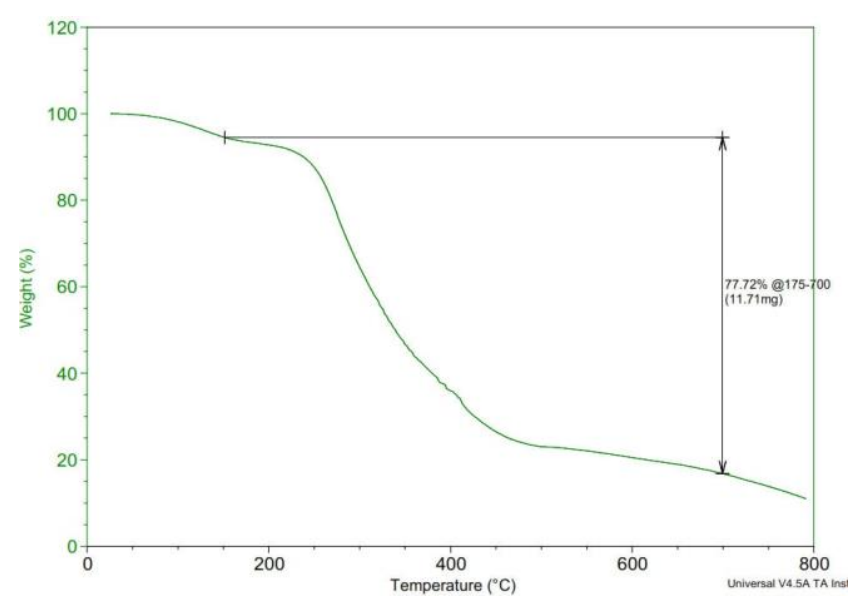

Figure 14. TGA thermogram of 30/70 PVA/gelatin blend film

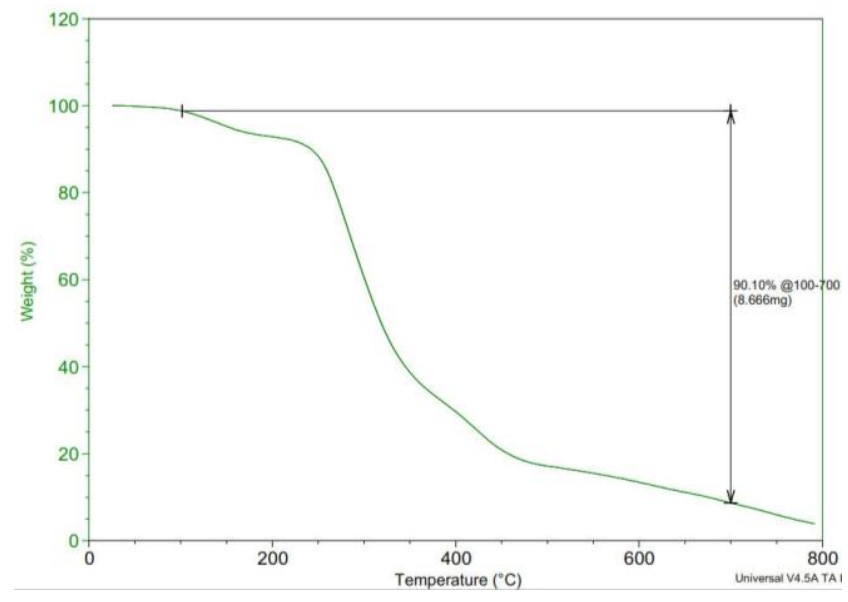

Figure 15. TGA thermogram of the 50/50 PVA/gelatin blend film

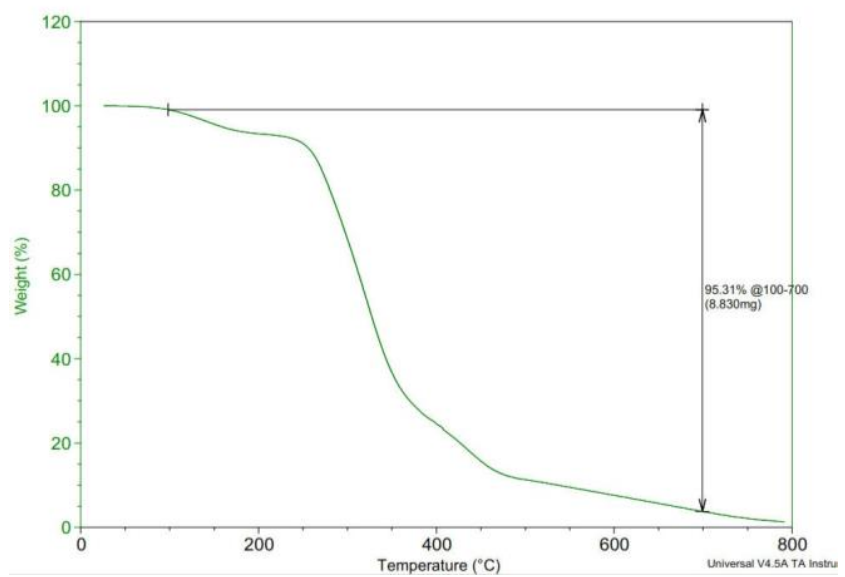

Figure 16. TGA thermogram of the 70/30 PVA/gelatin blend film

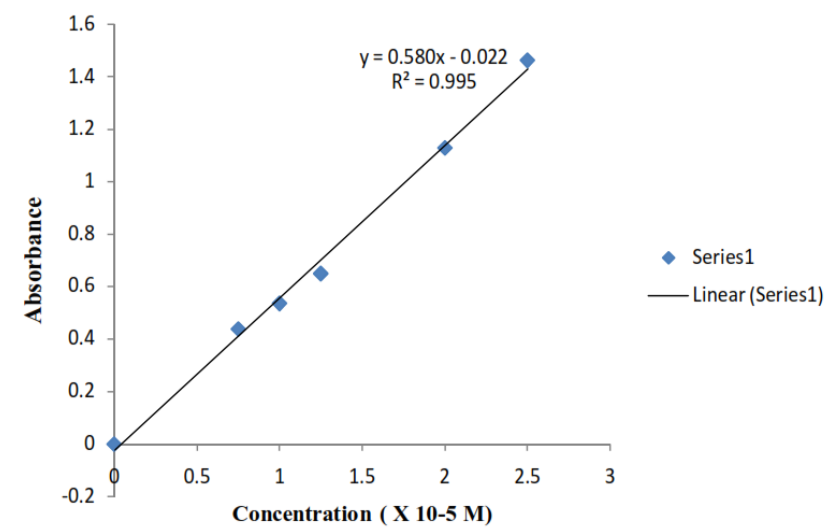

Figure 17. Calibration curve adsorption of methylene blue solutions onto 60/40 PVA/gelatin blend film 
Effect of contact time on adsorption of methylene blue

The contact time between the adsorbent and dye molecules is essential for determining the efficiency, kinetics, and equilibrium adsorption time (Shee 2011). From Figure 18, it is evident that initially, the amount of dye adsorbed increased rapidly but decreased in approaching equilibrium. At equilibrium, the graph completely flattens, which indicates little or no adsorption. It can be seen that the adsorption reaches equilibrium after 110 minutes when the percent dye adsorbed is $64 \%$.

The adsorption process can be divided into three regimes based on the duration of dye uptake. The first region shows speedy uptake, which gradually slows down in the second region. Finally, the dye uptake reached a plateau entering the third region. This is because an abundant amount of free surface area is available for adsorption in the first region. More molecules occupy and reduce the number of available sites, decreasing absorption rate as time elapses. Moreover, repulsive forces between adsorbate molecules on the adsorbent surface and those in the bulk solution keep increasing (Wanyonyi 2011).

\section{Effect of amount of adsorbent on adsorption}

The variation of the percent adsorption of $0.000025 \mathrm{M}$ methylene blue dye solution with the amount of PVAgelatin film (60/40 composition) is illustrated in Figure 19.

Increased weight of the PVA-gelatin film is positively correlated with increased the percent dye removal/ efficiency. At equilibrium, the percent dye removal is $43 \%$ for $0.25 \mathrm{~g}$ of PVA-gelatin film and $50 \%$ for $1.0 \mathrm{~g}$. When more adsorbent is used, binding/active sites become more available, thus increasing the adsorption efficiency. Wanyonyi (2011) and Shee (2011) have reported similar findings.

\section{Effect of initial dye concentration}

The adsorption kinetics is largely affected by the initial concentration of the adsorbed dye. This is due to the incorporation of driving force which is essential for overcoming mass transfer resistances between molecules in both the aqueous and the solid phases. The adsorption of methylene blue onto $0.25 \mathrm{~g}$ PVA-gelatin film was studied at three different concentrations, and the results are displayed in Figure 20.

Figure 20 demonstrates that dye adsorption is directly proportional to the initial methylene blue concentration. For a dye concentration $4 \mathrm{mg} / \mathrm{L}$, the equilibrium uptake of a $0.25 \mathrm{~g}$ PVA-gelatin film is $9.5 \mathrm{mg} / \mathrm{g}$, and when the dye concentration increases to $6 \mathrm{mg} / \mathrm{L}$, the uptake value is 14 $\mathrm{mg} / \mathrm{g}$. The correlation between dye adsorption and initial dye concentration is explained as follows. Increasing the dye concentration will increase the amount of driving force available to overcome resistance to mass transfer of the dye onto the film (Wanyonyi 2011). It also means increasing the number of dye molecules in the solution, thereby increasing the interaction between the dye and the adsorbent, which effectively increases adsorption. Shee (2011) also reported similar findings in the adsorption of methylene blue dye onto mangrove bark, mangrove leaves, and coconut husks.

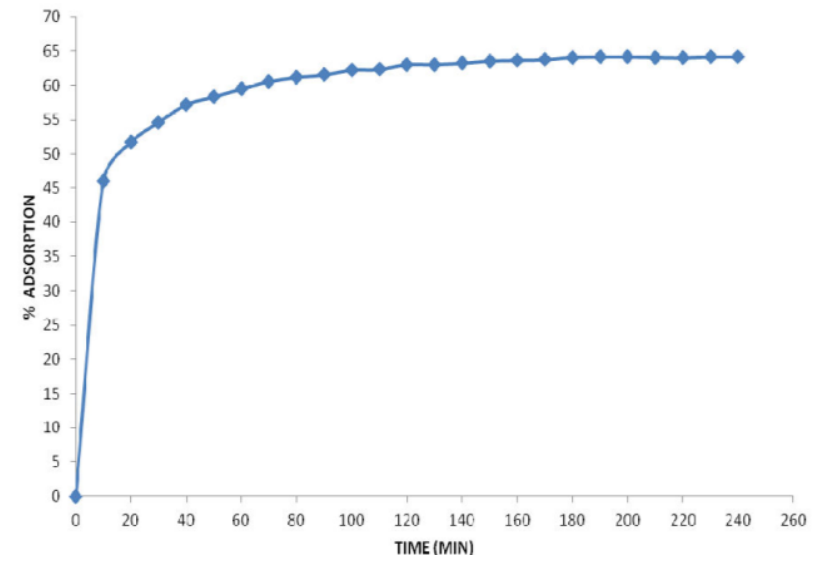

Figure 18. Effect of contact time on the adsorption of methylene blue dye solution, $2.0 \times 10^{-5} \mathrm{M}$ concentration onto 60/40 $\mathrm{PVA} /$ gelatin blend film

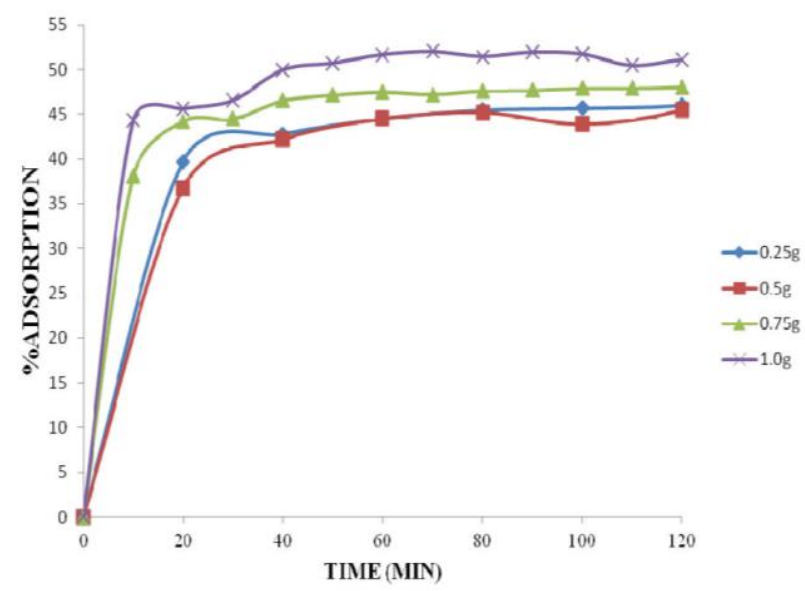

Figure 19. Effect of adsorbent weight on adsorption of $2.5 \times 10^{-}$ ${ }^{5} \mathrm{M}$ by PVA-gelatin film

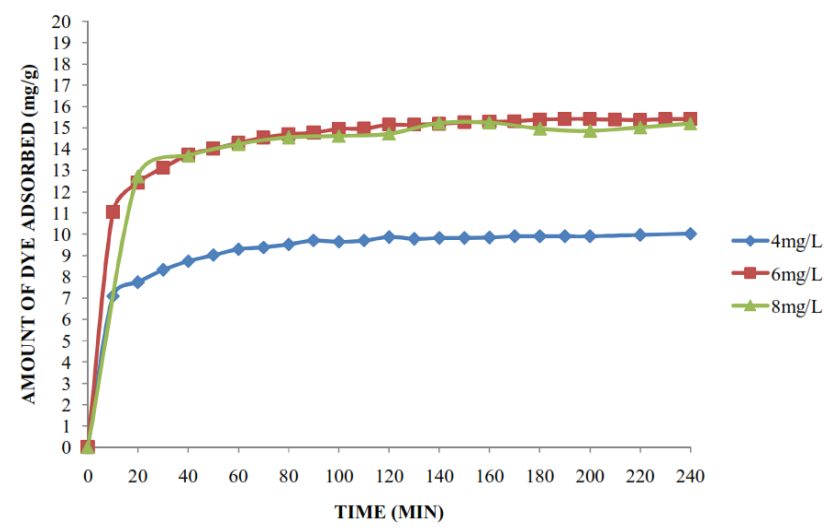

Figure 20. Effect of initial methylene blue dye concentration on equilibrium dye uptake using PVA/Gelatin blend film (60/40 composition) 
Nevertheless, only a very little change in the percent of equilibrium is observed when the initial methylene blue concentration is elevated from $6 \mathrm{mg} / \mathrm{L}$ to $8 \mathrm{mg} / \mathrm{L}$. Because the weight of the adsorbent remains the same throughout the time course, no change has occurred on the available binding sites. Therefore, at some point, all available binding sites are fully occupied by the dye molecules, so an increase in concentration will have no significant effect on adsorption.

\section{REFERENCES}

Ahmad M, Benjakul S. 2011. Characteristics of gelatin from the skin of unicorn leatherjacket (Aluterus monoceros) as influenced by acid pretreatment and extraction time. Food Hydrocoll 25: 381-388. DOI: 10.1016/j.foodhyd.2010.07.004

Akagündüz Y, Mosquera M, Giménez B, Alemán A, Montero P, GómezGuillén MC. 2014. Sea bream bones and scales as a source of gelatin and ACE inhibitory peptides. LWT - Food Sci. Technol 55: 579-585. DOI: 10.1016/j.lwt.2013.10.026

Amiza MA, Wan Maizatul Shima WM, Nor Hayati I, Nizaha Juhaida M. 2015. Optimization of gelatin extraction conditions from Cobia (Rachycentron canadum) skin and its physicochemical characteristics as compared to bovine gelatin. International Food Research Journal 22(1).

Avena-Bustillos RJ, Olsen CW, Olson DA, Chiou B, Yee E, Bechtel PJ, McHugh TH. 2006. Water vapor permeability of mammalian and fish gelatin films. J Food Sci 71: E202-E207. DOI: 10.1111/j.17503841.2006.00016.x

Chiellini E, Cinelli P, Fernandes EG, Kenawy E-RS, Lazzeri A. 2001 Gelatin-based blends and composites. morphological and therma mechanical characterization. Biomacromolecules 2: 806-811. DOI 10.1021/bm015519h

DinçEr MT, AğçAy ÖY, Sargin H, Bayram H. 2015. Functional properties of gelatin recovered from scales of farmed sea bass (Dicentrarchus labrax). Turk J Vet Anim Sci 39: 102-109. DOI 10.3906/vet-1406-68

Djabourov M, Leblond J, Papon P. 1988. Gelation of aqueous gelatin solutions. I. Structural investigation. J Phys 49: 319-332.

Elsergany RN. 2014. What is the difference between $\mathrm{Tm}$ and $\mathrm{Tg}$ for the crystalline state of a drug? https://www.researchgate.net/post/What_is_the_difference_between_ Tm_and_Tg_for_the_crystalline_state_of_a_drug

Gao X, Tang K, Liu J, Zheng X, Zhang Y. 2014. Compatibility and properties of biodegradable blend films with gelatin and poly(viny alcohol). J Wuhan Univ Technol- Mater Sci Ed 29: 351-356. DOI: 10.1007/s11595-014-0920-9

Gomez-Guillen MC, Turnay J, Fernandez-Diaz M, Ulmo N, Lizarbe MA Montero P. 2002. Structural and physical properties of gelatin extracted from different marine species; a comparative study. Food Hydrocoll 16: 25-34

Jiang L. 2013. Preparation of fish-scale gelatins by mild hydrolysis and their characterization. J Polym Env 21: 564-567.

Johnston-Banks F. 1990. Gelatin in Food Gels. Elsevier Applied Science, London.

Jongjareonrak A, Benjakul S, Visessanguan W, Tanaka M. 2006. Skin gelatin from bigeye snapper and brownstripe red snapper: Chemica compositions and effect of microbial transglutaminase on gel properties. Food Hydrocoll 20: 1216-1222. DOI: 10.1016/j.foodhyd.2006.01.006

Karayannakidis PD, Zotos A. 2014. Fish processing byproducts as a potential source of gelatin: A review. J Aquat Food Prod Technol 150527093845000. DOI: 10.1080/10498850.2013.827767

Karim AA, Bhat R. 2009. Fish gelatin: properties, challenges, and prospects as an alternative to mammalian gelatins. Food Hydrocoll 23: 563-576. DOI: 10.1016/j.foodhyd.2008.07.002

Khiari Z, Rico D, Martin-Diana BA, Barry-Ryan C. 2011. The extraction of gelatin from mackerel (Scomber scombrus) heads with the use of different organic acids. J Fish Sci 5: 52-63.
Kittiphattanabawon P, Benjakul S, Visessanguan W, Shahidi F. 2012. Effect of extraction temperature on functional properties and antioxidative activities of gelatin from shark skin. Food Bioprocess Technol 5: 2646-2654. DOI: 10.1007/s11947-010-0427-0

Mahmoodani F, Ardekani VS, Fern SS. 2014. Optimization of extraction and physicochemical properties of gelatin from pangasius catfish (Pangasius sutchi) skin. Sains Malaysiana 43: 995-1002.

Mendieta-Taboada O, Sobral PJ, Carvalho RA, Habitante AM. 2008 Thermomechanical properties of biodegradable films based on blends of gelatin and poly(vinyl alcohol). Food Hydrocoll 22: 1485-1492.

Muyonga J, Cole CG, Duodu K. 2004a. Extraction and physico-chemical characterization of Nile perch (Lates niloticus) skin and bone gelatin. Food Hydrocoll 18: 581-592. DOI: 10.1016/j.foodhyd.2003.08.009

Muyonga J H, Cole C G B, \& Duodu K G. 2004b. Characterization of acid soluble collagen from skins of young and adult Nile perch (Lates niloticus). Food Chemistry 85(1): 81-89. DOI: 10.1016/j.foodchem.2003.06.0

Nik Aisyah NM, Nurul H, Azhar ME, Fazilah A. 2014. Poultry as an alternative source of gelatin. Health Environ J 5: 37-49.

Nikoo M, Xu X, Benjakul S, Xu G, Ramirez-Suarez JC, Ehsani A, Kasankala LM, Duan X, Abbas S. 2011. Characterization of gelatin from the skin of farmed Amur sturgeon (Acipenser schrenckii). Int Aquat Res 3: 135-145.

Onyari JM, Huang SJ. 2009. Synthesis and properties of novel polyvinyl alcohol-lactic acid gels. J Appl Polym Sci 113: 2053-2061.

Pawde SM, Deshmukh K, Parab S. 2008. Preparation and characterization of poly(vinyl alcohol) and gelatin blend films. J Appl Polym Sci 109: 1328-1337. DOI: 10.1002/app.28096

Peesan M, Supaphol P, Rujiravanit R. 2005. Preparation and characterization of hexanoyl chitosan/polylactide blend films. Carbohydr Polym 60: 343-350. DOI: 10.1016/j.carbpol.2005.01.008

Sarbon NM, Badii F, Howell NK. 2013. Preparation and characterization of chicken skin gelatin as an alternative to mammalian gelatin. Food Hydrocoll 30: 143-151.

See SF, Hong PK, Ng KL, Wan Aida WM, Babji AS. 2010. Physicochemical properties of gelatins extracted from skins of different freshwater fish species. Int Food Res J 17: 809-816.

Shee A. 2011. Comparative Adsorption of Methylene Blue and Congo Red Dyes Onto Coconut Husks, Mangrove, and Polylactide Blended Films. [Thesis]. University of Nairobi, Department of Chemistry, Nairobi.

Shoulders MD, Raines RT. 2009. Collagen structure and stability. Annu Rev Biochem 78: 929-958. DOI: 10.1146/annurev.biochem.77.032207.120833

Silva GGD, Sobral PJA, Carvalho RA, Bergo PVA, Mendieta-Taboada O, Habitante AMQB. 2008. Biodegradable films based on blends of gelatin and poly (vinyl alcohol): Effect of PVA type or concentration on some physical properties of films. J Polym Environ 16: 276-285. DOI: $10.1007 / \mathrm{s} 10924-008-0112-9$

Singh P, Benjakul S, Maqsood S, Kishimura H. 2011. Isolation and characterization of collagen extracted from the skin of striped catfish (Pangasianodon hypophthalmus). Food Chem 124: 97-105. DOI: 10.1016/j.foodchem.2010.05.111

Tavakolipour H. 2011. Extraction and evaluation of gelatin from silver carp waste. World J Fish Mar Sci 3: 10-15.

Vanin FM, Sobral PJ, Menegalli FC, Carvalho RA, Habitante AM. 2005. Effects of plasticizers and their concentrations on thermal and functional properties of gelatin-based films. Food Hydrocoll 19: 807905.

Wang F, Guo E, Song E, Zhao P, Liu J. 2010. Structure and properties of bone-like- nanohydroxyapatite/ gelatin/polyvinyl alcohol composites. Adv Biosci Biotechnol 01: 185-189. DOI: 10.4236/abb.2010.13026

Wangtueai S, Noomhorm A. 2009. Processing optimization and characterization of gelatin from lizardfish (Saurida spp.) scales. LWT - Food Sci Technol 42: 825-834. DOI: 10.1016/j.lwt.2008.11.014

Wanyonyi WC. 2011. Biosorption Of Organic Dyes From Aqueous Solution Using Water Hyacinth (Eichhornia crassipes) From Lake Victoria. [Thesis]. University of Nairobi, Nairobi.

Wanyonyi WC, Onyari JM, Shiundu PM, Mulaa FJ. 2014. Enzymatic decolorization of malachite green dye by a newly isolated Bacillus cereus strain wwcp1. IOSR J Environ Sci Toxicol Food Technol (IOSR-JESTFT) 2 (12): 58- 64.

Zhang S, Li L. 2009. Materials Characterization Techniques. CRC Press, Boca Raton, Florida. 